\title{
Platelet-Tumor Cell Hybrid Membrane-Camouflaged Nanoparticles for Enhancing Therapy Efficacy in Glioma
}

Lingling $\mathrm{Wu},{ }^{1,2, *} \mathrm{Qin} \mathrm{Li}^{1}{ }^{1, *}$ Junjie Deng, ${ }^{3,4}$ Jinglan Shen, ' Weide $\mathrm{Xu},{ }^{3}$ Wei Yang, ${ }^{5}$ Bingyu Chen,' Yaoqiang Du, (D) Wei Zhang, ${ }^{6}$ Feihang Ge, ${ }^{6}$ Siyun Lei, 'Kaiqiang Li,

Zhen Wang $\mathbb{D}^{\prime}$

'Department of Transfusion Medicine, Allergy Center, Ministry of Education Key Laboratory of Laboratory Medicine, Zhejiang Provincial People's Hospital People's Hospital of Hangzhou Medical College, Hangzhou, 310014, People's Republic of China; ${ }^{2}$ Women's Hospital, School Of Medicine, Zhejiang University, Hangzhou, 3100I4, People's Republic of China; ${ }^{3}$ Zhejiang Engineering Research Center for Tissue Repair Materials, Wenzhou Institute, University of Chinese Academy of Sciences,

Wenzhou, Zhejiang, 325000, People's Republic of China; ${ }^{4}$ Oujiang Laboratory, Wenzhou, Zhejiang, 325000, People's Republic of China; ${ }^{5}$ Department of Biophysics, and Department of Neurosurgery of the First Affiliated Hospital, Zhejiang University School of Medicine, Hangzhou, People's Republic of China; ${ }^{6} \mathrm{Hangzhou}$ Chinese Academy of Sciences-Hangzhou Medical College Advanced Medical Technology Institute, Hangzhou, 310014, People's Republic of China

*These authors contributed equally to this work

Correspondence: Kaiqiang Li; Zhen Wang Zhejiang Provincial People's Hospital, Hangzhou, People's Republic of China Tel +86 057I-87666666

Fax +86 057I-85I 3 I 448

Email likaiqiang@hmc.edu.cn;

wangzhen@hmc.edu.cn
Purpose: Cell membrane-camouflaged nanoparticles (NPs) are drawing increasing attention because their surfaces acquire some characteristics of the cell membranes, making them a unique class of biomimetic materials for diverse applications. Modification of cell membrane or combination of different types of membranes can enhance their functionality.

Methods: We prepared platelet and tumor cell membrane camouflaged $\beta$-mangostin-loaded NPs, which were synthesized with platelet-C6 hybrid biomimetic coating, poly(lactic-coglycolic acid), and $\beta$-mangostin ( $\beta$-PCNPs). Then, we evaluated their targeting ability and anticancer activity against glioma in vitro and in vivo.

Results: Biomimetic coating enhanced active drug targeting and immune escape properties of nanocarrier in C6 and THP-1 cells, respectively, which improved their cytotoxicity. $\beta$ PCNPs were characterized to study the inherent properties of both source cells. Compared with bare $\beta$-NPs, $\beta$-PCNPs exhibited high tumor-targeting capability and induced apoptosis of C6 cells in vitro. Similarly, intravenous administration of drug through $\beta$-PCNPs resulted in enhanced tumor-targeting and exhibited excellent rate of inhibition of glioma tumor growth in mice. Moreover, the blood circulation time of drug in mice in the $\beta$-PCNP group was markedly prolonged and these mice exhibited better outcome than those in the $\beta$ NP group.

Conclusion: These results provide a new strategy of utilizing PCNPs as carriers for drug delivery, which improves the targeting efficiency and therapeutic efficacy of chemotherapeutic agents for glioma therapy.

Keywords: glioma, hybrid membrane, biomimetic, $\beta$-mangostin, targeted delivery, anticancer

\section{Introduction}

Glioblastoma multiforme (GBM) is the most common and aggressive malignant tumor of the central nervous system, tumor-targeting capability. ${ }^{1}$ Despite surgical resection in conjunction with current adjuvant therapies, it remains highly lethal, and the median survival period for GBM patients is only 14.6 months, with a 5-year survival rate of approximately $5 \%{ }^{2}$ To improve the chances of survival, chemotherapy is often administered to patients as an adjuvant treatment. ${ }^{3}$ During chemotherapy, the blood-brain barrier (BBB) and blood-brain tumor barrier (BBTB) constantly interact with the environment, which largely restricts efficient drug delivery to the glioma and reduces the therapeutic effects of the intervention. ${ }^{4}$ Therefore, the development of therapeutic agents and delivery systems that can 


\section{Graphical Abstract}
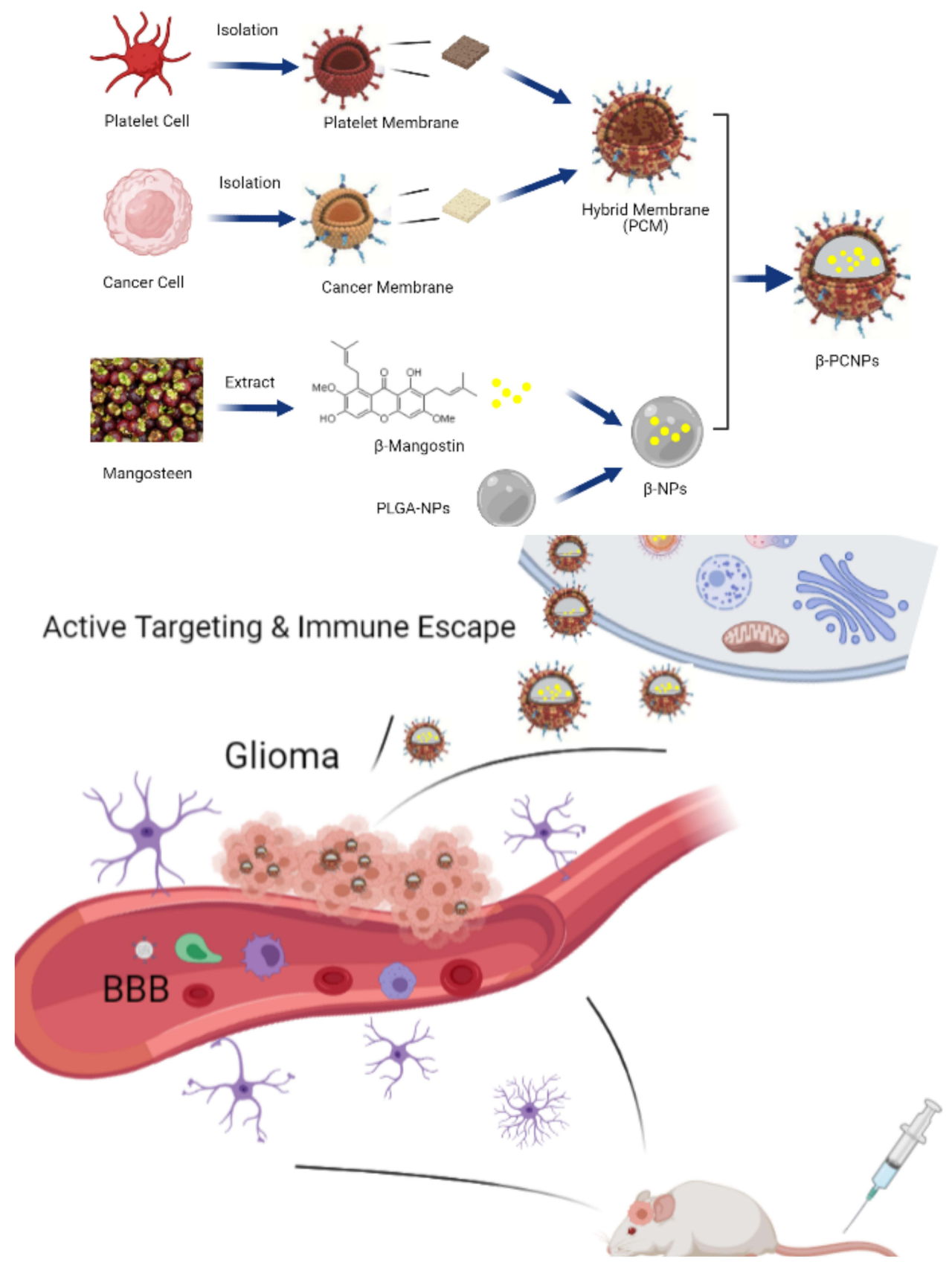

cross physiological and pathological barriers is urgently needed for the treatment of glioma.

Nanoparticle (NP)-based drug delivery systems have become a promising tool for improving the effectiveness and delivery of therapeutic drugs to tumors. 5,6 Nonetheless, the poor passive targeting ability and relatively short circulation time of nanocarriers limit their clinical application. ${ }^{7}$ Poly(lactic-co-glycolic acid)
(PLGA) is an excellent drug carrier owing to its biocompatibility, biodegradability, and safe degradation products, and has been widely used in drug delivery. ${ }^{8}$ Studies have extensively documented the functionalization of PLGA with various targeting ligands, such as peptides, antibodies, and nucleic acids. ' However, nanomaterials are easily intercepted by macrophages, resulting in poor immunocompatibility. ${ }^{10}$ 
Nature-inspired biomimetic nanocarriers are expected to have improved drug delivery applications. ${ }^{11,12}$ In recent years, cell membranes from red blood cells, ${ }^{13}$ white blood cells, ${ }^{14}$ platelets, ${ }^{15}$ macrophages, ${ }^{16}$ and cancer cells ${ }^{17}$ have been used to create nanocarriers. Cell membrane-based biomimetic nanomaterials, while retaining the bioengineering flexibility of the core, can be functionalized with various strategies that endow the nanomaterials with many desirable features. ${ }^{18-20}$ To overcome the functional limitations of using single-cell membranes to enhance the functionality of nanomaterials, researchers have developed specialized platforms to prepare hybrid membranes for camouflaging NPs by fusing membranes from different types of cells such as red blood cells and cancer cells, ${ }^{21}$ platelets and red blood cells, ${ }^{22}$ and cancer cells and macrophages. ${ }^{23}$ However, to the best of our knowledge, membranes from platelets and glioma cells have not been used to fabricate hybrid membranes. In this study, we developed tumortargeting NPs with excellent targeting and immune escape capabilities by fabricating platelet and glioma hybrid membranes to enhance the efficacy of cancer therapy.

Compared with traditional chemotherapeutics, natural fruit extracts have less toxicity, high drug compliance, and favorable antitumor efficiency. ${ }^{24-26} \beta$-Mangostin, a xanthone isolated from the pericarp of Garcinia mangostana Linn, has several bioactivities and pharmacological properties. ${ }^{27} \beta$-mangostin has anticancer activity against diverse cancer types including hepatocellular carcinoma, ${ }^{28}$ melanoma, ${ }^{29}$ and cervical cancer. ${ }^{30}$ Our previous study showed that $\beta$-mangostin, the major component of Garcinia mangostana L. extract, has excellent anti-proliferative effects in C6 glioma cells, which result from oxidative damage-induced cell death through PI3K/AKT/mTOR pathway inhibition. ${ }^{31}$ However, aqueous solubility, tumor selectivity or targeting, and BBB penetration rate of $\beta$-mangostin does not meet clinical requirements.

Considering the above, we synthesized $\beta$-mangostinloaded platelet-C6 glioma cell hybrid biomimetic membrane camouflaged-PLGA NPs ( $\beta$-PCNPs) for targeting cancers. We then studied the effects of the biomimetic properties, namely the interface potential and biological activity, of $\beta$-PCNPs, through systematic evaluation both in vitro and in vivo in a xenograft mouse model and an orthotopic glioma model.

\section{Materials and Methods}

\section{Materials}

Rat glial cell line C6, mouse hippocampal neuronal cell line HT22, and human monocytic leukemia cell line THP-1 were obtained from the Chinese Academy of Sciences Cell Bank; Garcinia mangostana L. (Thailand); PLGA was purchased from Lactel Absorbable Polymers; platelet-rich plasma was provided by volunteers; $\mathrm{BALB} / \mathrm{c}$ nude mice were obtained from Shanghai SLAC Laboratory Animal Co., Ltd.; mannitol, sucrose, Tris-HCL, $\mathrm{MgCl}_{2}, \mathrm{KCL}$, DiD, DiO, DiI, paraformaldehyde, phosphate buffered saline (PBS), and phorbol myristate acetate were obtained from Sigma Aldrich; protease inhibitor cocktail was procured from Bimake, Shanghai; BCA protein assay kit and CCK8 assay kit were supplied by Beyotime, China; fetal bovine serum (FBS) and penicillin-streptomycin were purchased from Gibco, USA; DMEM and RPMI 1640 were obtained from Hyclone, Shanghai.

\section{Preparation of $\beta$-Mangostin-Loaded NPs ( $\beta$-NPs)}

Ten kilograms of fresh Garcinia mangostana L. were separated and chopped, and dried for a week. The peel was pressed into a powder, and $\beta$-mangostin $(13.4 \mathrm{mg}$ ) was obtained by chromatography (Table S1; Figure S1-3). $\beta$-NPs were prepared using an ultrasonic emulsificationsolvent evaporation method. PLGA $(20 \mathrm{mg})$ dissolved in ethyl acetate $(500 \mu \mathrm{L})$, and $\beta$-mangostin $(2 \mathrm{mg})$ dissolved in DMSO $(200 \mu \mathrm{L})$, were mixed and used as the organic phase. The mixture was poured into $2 \mathrm{~mL} 1.5 \%$ polyvinyl alcohol (PVA) and subjected to ultrasonic treatment on ice for $10 \mathrm{~min}$ to form colostrum. Then, $2 \mathrm{~mL}$ of $0.5 \%$ PVA was added and the mixture was subjected to ultrasonic treatment on ice for another $10 \mathrm{~min}$ to form an emulsion. The formed emulsion was stirred $(1000 \mathrm{rpm})$ for $5 \mathrm{~h}$ at room temperature until the organic solvent was completely evaporated. The resulting emulsion was centrifuged at $18,000 \mathrm{~g}$ for $15 \mathrm{~min}$ at $4^{\circ} \mathrm{C}$ to collect yellow-colored NPs, which were washed three times, and stored at $-80^{\circ} \mathrm{C}$.

\section{Extraction of Platelet Membrane (PLTM) and $\mathrm{C} 6$ Cell Membrane (C6M)}

Human platelet membranes were derived from plateletrich plasma provided by volunteers. For purified platelet membranes, the obtained platelets were centrifuged at $4{ }^{\circ} \mathrm{C}$ and $100 \mathrm{~g}$ for $15 \mathrm{~min}$. The supernatant was centrifuged at $4^{\circ} \mathrm{C}$ and $800 \mathrm{~g}$ for $20 \mathrm{~min}$. Then, a lysis buffer $(25 \mathrm{mM}$ sucrose, $75 \mathrm{mM}$ mannitol, $1 \mathrm{mM} \mathrm{KCl}, 10 \mathrm{mM}$ Tris/HCl, 1 $\mathrm{mM} \mathrm{MgCl}_{2}$ ) and protease inhibitors $(1000 \times)$ were added, and the mixture was incubated on ice for $15 \mathrm{~min}$. Subsequently, platelets were repeatedly frozen and thawed five times. After the last freeze-thaw cycle, platelets were 
processed in an ultrasonic crusher for $5 \mathrm{~s}$, and the process was repeated five times at intervals of $5 \mathrm{~s}$. Platelets were then centrifuged at $21,000 \mathrm{~g}$ for $10 \mathrm{~min}$, resuspended in PBS, and stored in a refrigerator at $-40^{\circ} \mathrm{C}$.

C6 cells $\left(1 \times 10^{7}\right)$ were suspended in $5 \mathrm{~mL}$ of a lysis buffer containing $50 \mu \mathrm{L}$ protease inhibitor cocktail. After incubation in an ice bath for $20 \mathrm{~min}$, the cells were repeatedly frozen and thawed five times. Then, the cell lysate was centrifuged at $2000 \mathrm{~g}$ for $15 \mathrm{~min}$ at $4^{\circ} \mathrm{C}$, and the collected supernatant was further centrifuged at 21,000 $\mathrm{g}$ for $30 \mathrm{~min}$. Finally, the white precipitate containing the plasma membrane was stored at $-40^{\circ} \mathrm{C}$ for subsequent experiments.

\section{Preparation and Characterization of Hybrid Membrane-Coated NPs (PCNPs)}

$\mathrm{DiD}(10 \mathrm{mg} / \mathrm{mL})$ and $\mathrm{DiO}(10 \mathrm{mg} / \mathrm{mL})$ were added to PLTM and C6M suspensions, respectively, and incubated for $1 \mathrm{~h}$ at room temperature on a laboratory shaker. These mixtures were centrifuged at $4^{\circ} \mathrm{C}$ and $21,000 \mathrm{~g}$ for $10 \mathrm{~min}$ to remove free dyes, and to obtain DiD-labeled PLTM and DiO-labeled C6M. From each of these dye-labeled membrane solutions, $500 \mu \mathrm{L}$ was taken, mixed, and pushed 11 times using the liposome extruder. Another $500 \mu \mathrm{L}$ of each solution was mixed to obtain PLTM\&C6M solution. Finally, the two solutions were placed on glass slides and imaged under a confocal laser scanning microscope (CLSM).

The platelet membrane dissolved in $1 \mathrm{~mL}$ PBS and $0.1 \mu \mathrm{L} 10 \mathrm{mg} / \mathrm{mL}$ DiD (excitation $/$ emission $=644 / 663$ $\mathrm{nm})$ and DiI (excitation/emission $=549 / 565 \mathrm{~nm}$ ) dissolved in DMSO were incubated on a shaking bed at room temperature. After $1 \mathrm{~h}$, the resulting solution was centrifuged thrice at $4^{\circ} \mathrm{C}$ and $21,000 \mathrm{~g}$ for 10 minutes to remove the free dye. Concentrations of membrane proteins were measured by BCA assay kit. C6M was added to PLTM at following weight ratios respectively: 5:1, $3: 1,1: 1$, and $0: 1$. The mixture was repeatedly (11 times) passed through $400 \mathrm{~nm}$ and $200 \mathrm{~nm}$ polycarbonate membrane to fuse cell membranes. By adding $100 \mathrm{ul}$ solution into 96 well plate, the results were determined by enzyme reader at the excitation wavelength of 525 $\mathrm{nm}$, between $550 \mathrm{~nm}$ and $750 \mathrm{~nm}$ emission band, the fluorescence spectrum of the sample was read every 10 $\mathrm{nm}$, and the fluorescence curve was drawn.

The composite cell membrane solution (PLTM-C6M) obtained was mixed with the $\beta$-NPs and incubated overnight. Then, this solution was pushed through polycarbonate membranes of $400 \mathrm{~nm}$ and $200 \mathrm{~nm} 11$ times by using a liposome extruder to obtain membrane-coated NPs loaded with $\beta$-mangostin. Hydrodynamic size and zeta potential of the prepared membrane-coated NPs were characterized using a zetasizer. For transmission electron microscopy (TEM), $0.2 \mathrm{mg} / \mathrm{mL}$ sample $(10 \mu \mathrm{L})$ was dropped onto a carbon-coated grid after cleaning it with plasma. The grid was then rinsed with deionized water and $2 \%$ uranyl acetate solution in water $(10 \mu \mathrm{L})$ was dropped on the grid for $2 \mathrm{~min}$ and removed using a filter paper. The staining step was repeated three times prior to imaging with TEM at $200 \mathrm{KV}$.

\section{In vitro Stability of NPs and Drug Release from $\beta$-PCNPs}

To evaluate their stability, PCNPs were suspended in water, $1 \times \mathrm{PBS}$, and $10 \%$ fetal bovine serum at a final concentration of $1 \mathrm{mg} / \mathrm{mL}$. After one week, size of NPs was determined using zetasizer to identify aggregation. For evaluation of drug release, $\beta$-NPs or $\beta$-PCNPs were placed in a dialysis bag ( $\mathrm{MWCO}=12-14 \mathrm{kDa})$, which was put in $30 \mathrm{~mL}$ of release medium $\left(\mathrm{H}_{2} \mathrm{O}\right.$, PBS, and $10 \%$ FBS) containing $0.1 \%$ Tween 80 was added to a $50 \mathrm{~mL}$ centrifuge tube. The in vivo physiological environment was simulated by placing the centrifuge tube on a shaker set at $37^{\circ} \mathrm{C}$ and $200 \mathrm{rpm}$. After a predetermined time $(0,2$, 4, 8, 24, 48, 72, 96, 120, 144, and $168 \mathrm{~h}$ ), all solutions were extracted and replaced with $30 \mathrm{~mL}$ of the same solution. The absorbance of the released $\beta$-mangostin was measured at $360 \mathrm{~nm}$ using a microplate reader.

\section{Active Targeting and Immune Escape Characteristics of PCNPs}

Cellular uptake of NPs in C6 cells and macrophages was quantitatively analyzed by laser scanning confocal microscopy (LSCM) and flow cytometry. For this study, NPs were fluorescently labeled by incorporating $0.1 \mathrm{wt} \% \mathrm{DiD}$ into the PLGA cores. C6 cells were seeded on a 6 -well plate $\left(5 \times 10^{5}\right.$ per well) and cultured for $12 \mathrm{~h}$, whereas THP-1 cells were maintained in RPMI 1640 medium supplemented with $10 \%$ FBS and $1 \%$ penicillin-streptomycin at $37^{\circ} \mathrm{C}$ and $5 \% \mathrm{CO}_{2}$. Cells were differentiated into macrophage-like phenotype cells by culturing them with $100 \mathrm{ng} / \mathrm{mL}$ phorbol myristate acetate (PMA) for $48 \mathrm{~h}$. Cell culture media were then replaced with fresh media containing NPs (PLGA Nanoparticles), PNPs (Platelet cell membrane coated PLGA nanoparticles), CNPs (C6 cell membrane coated PLGA nanoparticles), and PCNPs (Platelet-C6 hybrid cell 
membrane coated PLGA nanoparticles). After 4 $\mathrm{h}$ incubation, cells were washed twice with PBS and fixed with pre-cooled 4\% paraformaldehyde in PBS for $15 \mathrm{~min}$, labeled with DAPI for $15 \mathrm{~min}$, and then washed thrice with PBS. Finally, $10 \mu \mathrm{L}$ of an anti-fluorescence quenching agent was added cells were observed using CLSM. For quantitative measurement, adherent cells were trypsinized into a single cell suspension, suspended in $0.5 \mathrm{~mL}$ of PBS $(0.01 \mathrm{M}, \mathrm{pH} 7.4)$, and analyzed by flow cytometry.

\section{In vitro Antitumor Activity}

We evaluated the cytotoxicity of the prepared nanoscale systems against $\mathrm{C} 6$ cells and mouse hippocampal neuronal HT22 cells by using an in vitro CCK8 assay kit. First, we evaluated the toxicity of PCNPs on HT22 cells. Briefly, HT22 cells were seeded in 96-well plates $\left(1.0 \times 10^{4}\right.$ cells per well) and cultured in a $\mathrm{CO}_{2}$ incubator for $24 \mathrm{~h}$. The culture medium was aspirated, and cells were then incubated with $100 \mu \mathrm{L}$ culture medium containing PCNPs at different concentrations $(2,4,8$, and $16 \mathrm{mg} / \mathrm{mL})$ for 24 h. The wells without samples were considered the control group, whereas the wells without cells and samples were considered the blank group. Before CCK8 assay, culture medium in each well was removed and cells were washed three times with $1 \times \mathrm{PBS}$. CCK $8(10 \mu \mathrm{L})$ was then added to each well, and the plates were incubated in an incubator for 1-4 h. Absorbance was measured at $562 \mathrm{~nm}$ using a microplate reader, and cell survival was calculated. CCK8 assay was also used to evaluate the cytotoxicity of $\beta$-mangostin-loaded NPs coated with different cell membranes in C6 cells. Briefly, C6 cells were seeded in 96-well plates at $1.0 \times 10^{4}$ cells per well and cultured for 24 h. Then, the NP solutions (NPs, PNPs, CNPs, PCNPs) loaded with different concentrations of $\beta$-mangostin (5, $10,15,20$, and $25 \mu \mathrm{g} / \mathrm{mL}$ ) were added and cells were incubated for $24 \mathrm{~h}$; the wells without samples were considered the control group, whereas the wells without cells and samples were considered the blank group. Cell viability was evaluated as described above.

\section{In vivo Antitumor Activity in Subcutaneous Glioma Model}

All animals were raised in a specific pathogen-free environment. This project was approved by the Medical Ethics Committee of Zhejiang Provincial People's Hospital. We acknowledge that the project was performed according to international, national, and institutional rules for animal experiments, clinical studies, and biodiversity rights. C6 cell suspension in exponential growth phase was collected and used to develop a subcutaneous tumor model in mice. Cell density was adjusted to obtain a final concentration of $5 \times 10^{6}$ cells $/ \mathrm{mL}$ after mixing the cell suspension with Matrigel at 2:1. Sixty BALB/c nude mice (male; 4-weekold; $18-22 \mathrm{~g}$ ) were randomly divided into six groups of 10 mice each. The above prepared C6 cell suspension $(200 \mu \mathrm{L})$ was injected into the subcutaneous tissue of the right back of each nude mouse. When the tumor volume reached approximately $80-100 \mathrm{~mm}^{3}$, the mice were treated with PBS, $\beta$-mangostin, $\beta$-NPs, $\beta$-PNPs, $\beta$ CNPs, and $\beta$-PCNPs every other day at the same dose $(5 \mathrm{mg} / \mathrm{kg}, 200 \mu \mathrm{L})$ for seven days. The weight and tumor growth of the nude mice were monitored every two days after the first injection. The tumor length and diameter were measured using a Vernier caliper, and the volume was calculated according to the formula $\mathrm{V}=$ (length $\times$ width $\left.^{2}\right) / 2$. On the 18 th day, the mice were sacrificed for biochemical and pathological analyses and toxicological evaluation. Tumors were stripped, weighed, and photographed.

\section{In vivo Imaging}

After administration of NPs, healthy BALB/c nude mice were imaged using the EXplore Optix MX animal imaging system to visualize the distribution of NPs in vivo and their accumulation in the brain regions. Excitation and emission wavelengths used for imaging were $580 \mathrm{~nm}$ and $692 \mathrm{~nm}$, respectively. To establish the $\mathrm{C} 6$ intracranial orthotopic glioblastoma mouse model, mice were anesthetized using 3.5\% chloral hydrate $(1.5 \mathrm{~mL} / 100 \mathrm{~g}$ body weight). The head (the area to be inoculated) was cleaned with $70 \%$ ethanol and opened with a sterilized scalpel. C6 cell suspension (500 $\mu \mathrm{L} ; 1 \times 10^{5}$ cells in $10 \%$ DMEM) was injected into the striatum at a depth of $3 \mathrm{~mm}$ from the dural surface. Twenty days after the orthotopic glioma model was established, the mice were randomly divided into four groups and each mouse was injected with $200 \mu \mathrm{L}$ of DiD-labeled NPs, PNPs, CNPs, and PCNPs via the tail vein. At $24 \mathrm{~h}$ after injection, the mice were anesthetized with isoflurane and imaged from the back.

\section{In vivo Antitumor Activity in Orthotopic Glioma Model}

All animal experiments were conducted following the guidelines approved by the Laboratory Animal Management and Ethics Committee of Zhejiang Provincial People's Hospital. 
An orthotopic glioma model was established according to the above method. Seven days after the model was established, mice were randomly divided into six groups (PBS, $\beta$ mangostin, $\beta$-NPs, $\beta$-PNPs, $\beta$-CNPs, and $\beta$-PCNPs) and administered the same dose and injection as the mice with the subcutaneous tumor. The overall survival was monitored in all groups. On the 20th day after modeling, one mouse was randomly selected from each group, and the brains and major organs were sampled for H\&E staining. The remaining mice in each group were observed until their death.

\section{Statistical Analysis}

All statistical tests were performed in GraphPad Prism 8 software. For comparison between the groups, unpaired $t$-test was used. Results of more than three independent repeated experiments were expressed as mean \pm SEM. Statistically significant differences between groups were considered at $\mathrm{P}<0.05$ (denoted by $*$ ), $\mathrm{P}<0.01$ (denoted by $* *)$, and $\mathrm{P}<0.001$ (denoted by $* * *$ ).

\section{Results \\ PLT-C6 Hybrid Cell Membrane Characterization}

As shown in Figure 1A, when the ratio of $\mathrm{C} 6$ membrane in the PLT-C6 hybrid membrane was increased, fluorescence recovery was observed until $590 \mathrm{~nm}$; thereafter, increased in comparison with the PLT membrane, there was a recovery of fluorescence at $590 \mathrm{~nm}$, whereas the fluorescence gradually decreased until $670 \mathrm{~nm}$. This indicated weakening of the FRET interaction in the hybrid PLT-C6 membrane due to the interspersing of the two membrane materials. We then fabricated a PLT-C6 hybrid membrane by using PLT cell membrane labeled with DiD and C6 cell membrane labeled with DiI at 1:1 mass ratio. The PLT cell membranes labeled with DiD appeared red and the C6 glioma membranes incubated with DiI appeared green. The mixture of the dye labeled PLT and C6 membranes exhibited distinct red and green light spots. However, when membranes were fused to form a hybrid membrane, a significant merging of the fluorescent signals derived from DiD and DiI was observed (Figure 1B). These results suggest the successful fusion of the natural PLT membrane and C6 cell membrane.

\section{Preparation and Characterization of PCNPs} NPs were wrapped in PLTM, C6M, and PLTM-C6M using a cell membrane extrusion method to obtain PNPs, CNPs, and PCNPs, respectively. ${ }^{32}$ The TEM images (Figure 1C) of PCNPs negatively stained with uranyl acetate appeared as hollow and spherical particles with a diameter of around $130 \mathrm{~nm}$ and a uniform $\sim 10$-nm-thick outer shell, indicating the presence of a hybrid membrane; these results were consistent with those obtained by dynamic light scattering (DLS) analysis of particle size (Figure 1F). DLS analysis showed that the PCNPs were larger than the bare core NPs (131.7 nm vs $121.9 \mathrm{~nm}$; Figure 1D). Moreover, their surface zeta potential changed from $-43.9 \mathrm{mV}$ to $-10.3 \mathrm{mV}$ after the hybrid membrane coating (Figure 1E), confirming the presence of a charged outer membrane layer similar to that of the PLT-C6 hybrid membrane. Successful extraction of the membranes was confirmed by the presence of protein markers specific to the membranes of the platelets and C6 glioma cells in the hybrid PLT-C6 membrane (Figure 1G). These results show that the PLT-C6 hybrid membrane was successfully prepared and coated onto the PLGA NPs.

\section{Active Targeting and Immune Escape Characteristics of PCNPs}

Confocal laser-scanning microscope images (Figure 2A) showed that DiD was mainly localized in the cytoplasm of the C6 glioma cells after incubation of the cells with DiDPCNPs for $4 \mathrm{~h}$. Moreover, cells incubated DiD-PCNPs showed brighter red fluorescence than the NP-treated cells. Cell uptake of DiD in C6 cells was further investigated by using flow cytometry (Figure $2 \mathrm{~B}$ and $\mathrm{C}$ ). DiD fluorescence intensity in the C6 cells treated with DiD-PNPs and DiDCNPs was approximately 1.9 times stronger than that of cells treated with bare DiD-NPs. Similarly, DiD fluorescence intensity in C6 cells treated with DID-PCNPs was approximately 3.1 times stronger than in cells treated with bare DiD-NPs, indicating that PLT-C6 hybrid cell membranecoated NPs have good target recognition capabilities. To evaluate their immune escape properties, internalization of DiD-PCNPs by macrophages was studied by CLSM imaging. A very low level of red fluorescence was observed in C6 cells treated with DiD-PCNPs (Figure 2D). Notably, this fluorescence signal was weaker than that observed in the DiD-NP-treated group. Quantitative analysis by flow cytometry indicated that the fluorescence intensity in the DiDNP group was 2.3-fold stronger than that of DiD-PCNP group (Figure 2E and F), confirming the good immune escape ability of PCNPs. 


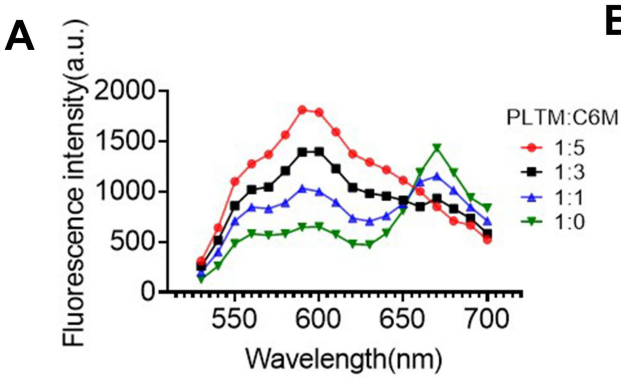

B

C

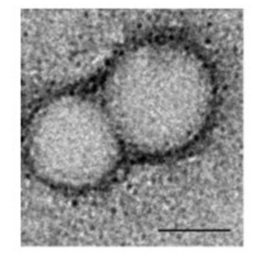
NPS
D

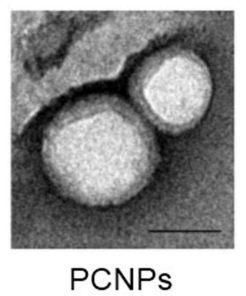

$\mathbf{F}$

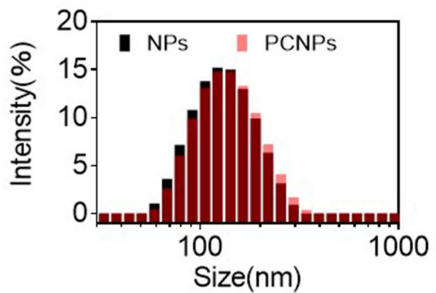

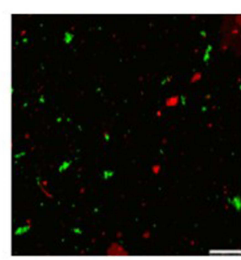

PLTM\&C6M

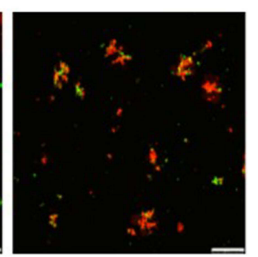

PLTM-C6M

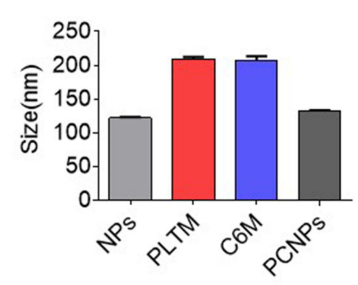

E

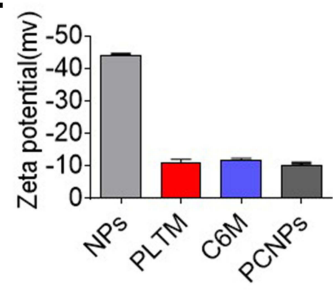

\section{G}

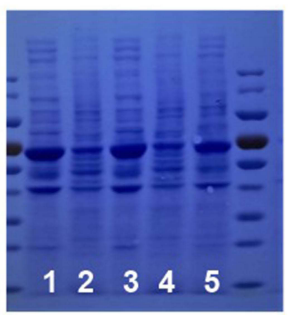

Figure I Fabrication and physicochemical characterization of PCNPs. (A) Platelet membrane was doped with a pair of FRET membrane probes and fused with increasing amounts of $\mathrm{C} 6$ cell membrane. The recovery of fluorescence emission from the donor was monitored at the lower emission peak $(525 \mathrm{~nm}, \mathrm{PLTM}$ : C6M $=$ platelet membrane protein to C6 cell membrane ratio). (B) Laser scanning confocal microscopy images of either a mixture of PNPs and CNPs or of the PCNPs (red = C6 cell membrane, green $=$ platelet membrane; scale bar $=10 \mu \mathrm{m})$. (C) Representative TEM images of bare PLGA cores and PCNPs, negatively stained with uranyl acetate $($ scale bar $=100$ nm). (D and E) Z-average size and surface zeta potential of bare PLGA cores, PNPs, CNPs, and PCNPs, as measured by DLS. (F) Z-average size of bare PLGA cores and PCNPs. (G) Protein content visualization of I: platelet, 2: C6 cells, 3: PNPs, 4: CNPs, and 5: PCNPs, run on SDS polyacrylamide gel electrophoresis at equivalent protein concentrations followed by Coomassie Brilliant Blue staining. Data are represented as mean \pm S.D of three independent experiments.

\section{Drug Loading and in vitro Release of $\beta$ - Mangostin by PCNPs}

Bare core PCNPs and $\beta$-PCNPs were synthesized as outlined in Figure S4. The encapsulation efficiency (EE) and loading content (LC) of the $\beta$-mangostin-loaded PCNPs are summarized in Figure $3 \mathrm{~A}$ and $\mathrm{B}$. Although the highest LC (15.1\%) was achieved when the mass ratio of $\beta$ mangostin: PLGA-NPs was $1: 3$, the EE was only $75.6 \%$, leading to wastage of $\beta$-mangostin. A good balance was achieved at 1:4 ratio, with $\mathrm{LC}$ and $\mathrm{EE}$ of $13.08 \%$ and $82.3 \%$, respectively. As shown in Figure 3C, $\beta$ mangostin-loaded NPs were stable in $\mathrm{H}_{2} 0$, PBS, and $10 \%$ FBS, with a particle size of approximately $190 \pm 5$ $\mathrm{nm}$ and PDI $<0.1$. The in vitro release profiles of $\beta$ mangostin loaded into NPs and PCNPs were investigated in $10 \%$ FBS (Figure 3D). The $\beta$-NPs showed a burst drug release in the initial $8 \mathrm{~h}$ of the experiment, and reached a cumulative release of $50.4 \pm 6.7 \%$ after $24 \mathrm{~h}$. This can be attributed to their porous structures. However, in case of $\beta$ PCNPs, this burst release was inhibited, which can be ascribed to the blockage of $\beta$-mangostin release due to presence of hybrid membrane around the particles.

\section{In vitro Anticancer Activity}

Next, the in vitro therapeutic effects of $\beta$-PCNPs were evaluated. First, the CCK8 assay results demonstrated the biocompatibility of PCNPs (Figure 3E) and antitumor efficacy and targeting ability of $\beta$-PCNPs against $\mathrm{C} 6$ glioma cells (Figure 3F). At a $\beta$-mangostin concentration of $10 \mu \mathrm{g} / \mathrm{mL}$, C6 glioma cells treated with $\beta$-PCNP showed significantly low viability $(17.0 \%)$, whereas the viability of C6 glioma cells treated with $\beta$-NPs was relatively high (47.54\%). Next, we studied induction of apoptosis in C6 cells treated with $\beta$ PCNPs. $C 6$ cells were incubated with DMEM, $\beta$-NPs, $\beta$-PNPs, $\beta$-CNPs, and $\beta$-PCNPs for $24 \mathrm{~h}$, stained with Annexin V-FITC/ PI, and analyzed by flow cytometry. PI and FITC are known to 
A
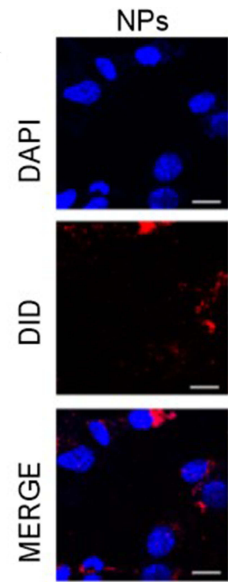

D
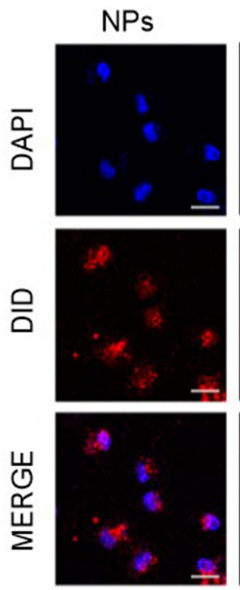

PNPs
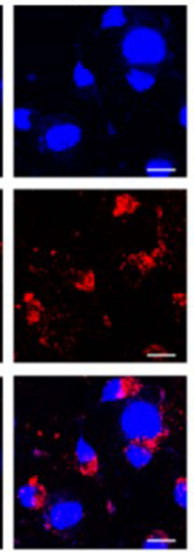

PNPs
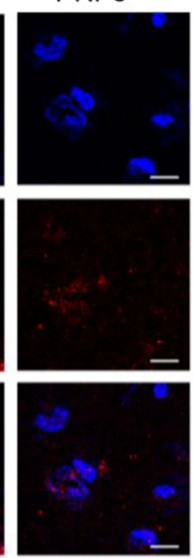
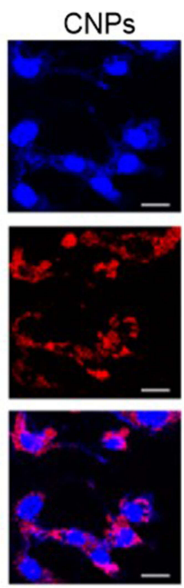

CNPs
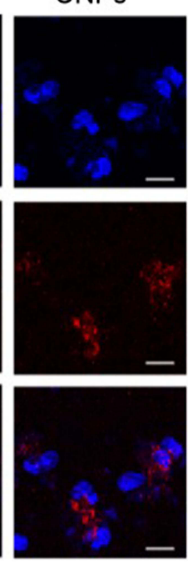
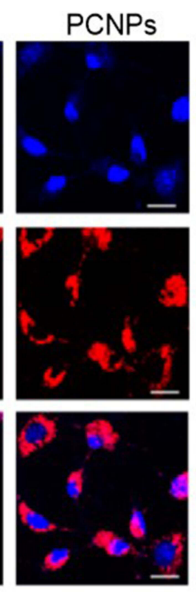

PCNPs
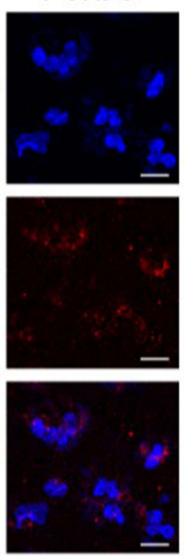

B

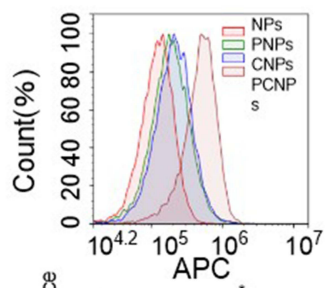

C

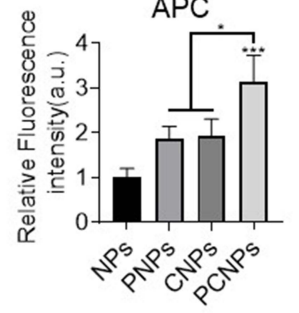

E

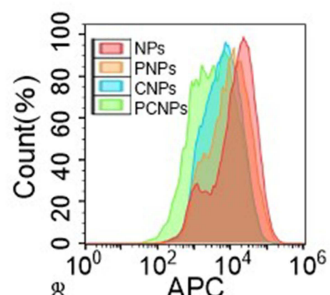

$\mathbf{F}$

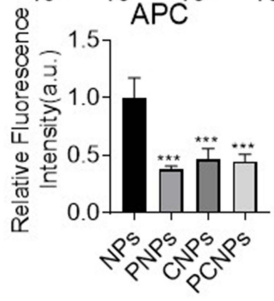

Figure 2 Homotypic targeting and immune escape ability of $\beta$-PCNPs. (A) Confocal fluorescence imaging of dye-labeled bare PLGA cores (NPs), PNPs, CNPs, and PCNPs after incubation with C6 cells (red = nanoparticles, blue = nuclei; scale bars $=20 \mu \mathrm{m}$ ). (B and C) Binding of fluorescently labeled bare NPs, PNPs, CNPs, and PCNPs to C6 glioma cells, as analyzed by flow cytometry. (D) Confocal fluorescence imaging of dye-labeled NPs, PNPs, CNPs, and PCNPs after incubation with THP-I cells (red = nanoparticles, blue $=$ nuclei; scale bars $=20 \mu \mathrm{m}) .(\mathbf{E}$ and $\mathbf{F})$ The uptake of fluorescently labeled NPs, PNPs, CNPs, and PCNPs when incubated with human macrophage-like cells, as analyzed by flow cytometry. Data are represented as mean \pm S.D of three independent experiments; $* P<0.05, * * * P<0.00$ I.

interfere with each other in the apoptosis assay; therefore, unstained C6 cells and C6 cells stained with Annexin V or PI only were also processed for compensation. Compared with the control groups, $\beta$-PCNPs strongly induced apoptosis of 66 cells. After $24 \mathrm{~h}$ of incubation with $\beta$-PCNPs, approximately half of $\mathrm{C} 6$ cells were in the late apoptotic stage (Figure 3G, upper right quadrant, Annexin V, PI+). However, in other groups, the percentage of late apoptotic C6 cells was significantly lower. Overall, these studies showed that $\beta$-PCNPs possess excellent in vitro antitumor effect on $\mathrm{C} 6$ cells, which makes them a promising candidate for in vivo chemotherapy.

\section{In vivo Antitumor Activity in Subcutaneous C6 Glioma Model}

Based on the encouraging results of in vitro antitumor activity of $\beta$-PCNPs, a subcutaneous C6 glioma model was used to investigate the antitumor efficacy of $\beta$-PCNPs in vivo.
PBS, free $\beta$-mangostin, $\beta$-NPs, $\beta$-PNPs, $\beta$-CNPs, and $\beta$ PCNPs were injected into tumor-bearing mice through the caudal vein. All formulations were prepared to provide the same $\beta$-mangostin dosage of $5 \mathrm{mg} / \mathrm{kg}$. As shown in Figure $4 \mathrm{~A}$, free $\beta$-mangostin exhibited little inhibition of tumor growth due to drug resistance, whereas $\beta$-NPs, $\beta$ PNPs, $\beta$-CNPs, and $\beta$-PCNPs suppressed the tumor growth to different degrees. The change in body weights of mice in each treatment group was consistent with the change trend observed in mice of the PBS group (Figure 4B). No obvious toxic reactions or deaths were observed during the experiment, assuring a good safety profile. After sacrifice at the end of the experiment, the tumor tissue was examined after cardiac perfusion with $4 \%$ paraformaldehyde (Figure $4 \mathrm{C}$ and D); the size of the tumor was in the order PBS $>$ free $\beta$ mangostin $>\beta$-NPs $>\beta$-PNPs $>\beta$-CNPs $>\beta$-PCNPs. Based on these findings, it can be suggested that the PLT-C6 

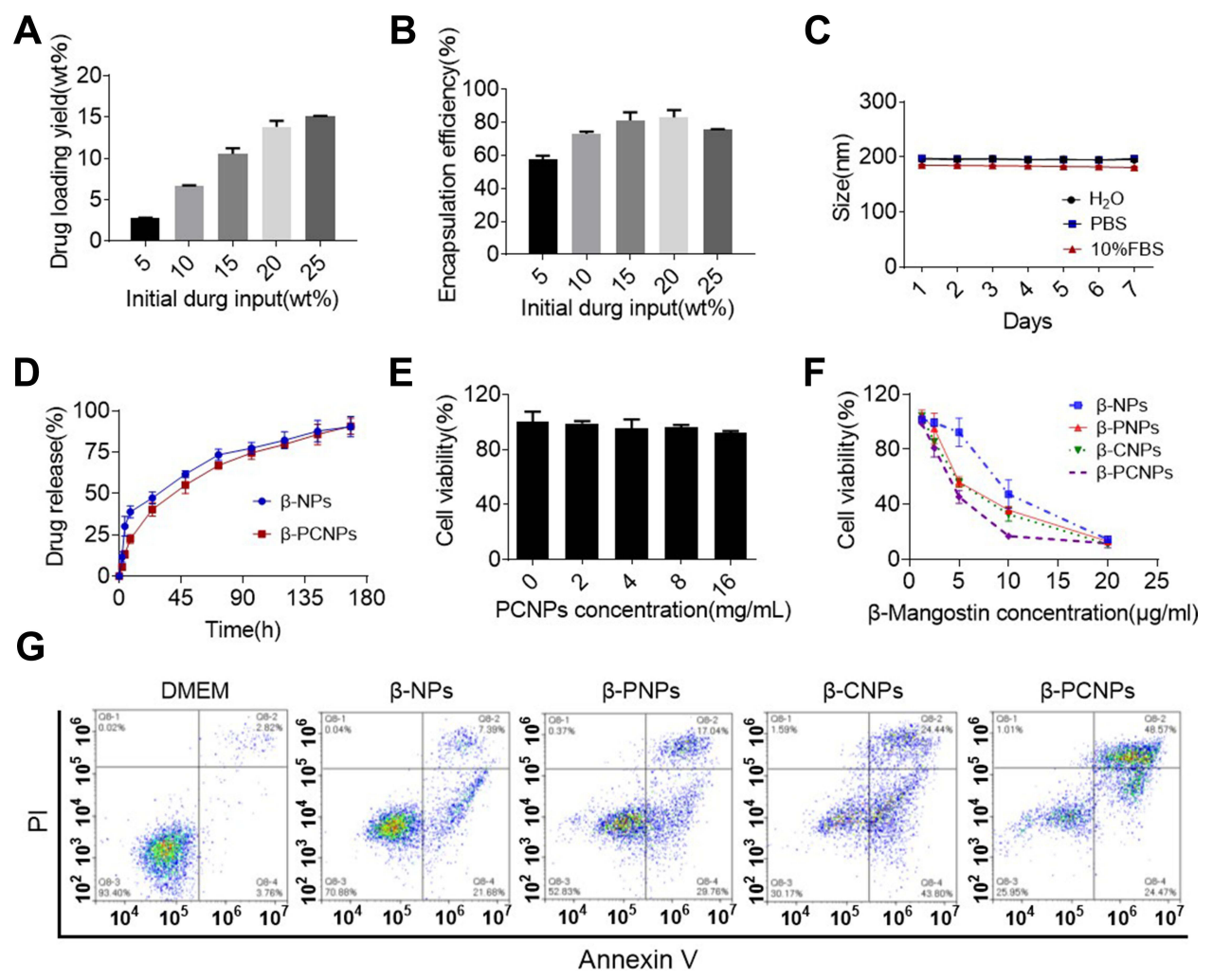

Figure 3 In vitro antitumor activity of different nanoparticles. (A and B) $\beta$-Mangostin loading capacity and encapsulation efficiency of PCNPs when $\beta$-mangostin concentrations were $75,150,225,300$, and $375 \mu \mathrm{g} / \mathrm{mL}$. (C) Z-average size of PCNPs over 7 days in $\mathrm{H}_{2} \mathrm{O}$, PBS, and I0\% FBS. (D) $\beta$-Mangostin release from $\beta$-NPs and $\beta$ PCNPs in 10\% FBS. (E) CCK8 assay was used to measure HT22 cell viability after treatment with different concentrations of PCNPs. (F) CCK8 assay was used to measure C6 cell viability after treatment with different concentrations of $\beta$-PCNPs. (G) C 6 cell apoptosis was measured using flow cytometry. Data are presented as mean \pm S.D of three independent experiments.

hybrid membrane coating on the surface of PLGA NPs could enhance their uptake by cancer cells, resulting in accumulation of the formulation in the tumors. We also performed immunofluorescent TUNEL staining assay to assess tumor cell apoptosis (Figure 4E). Although apoptotic (green) cells were seen in all groups of mice that received $\beta$ PNPs, $\beta$-CNPs, or $\beta$-PCNPs, apoptosis was much more evident in the $\beta$-PCNP treatment group. These results indicate that $\beta$-PCNPs can act as an effective drug delivery platform for tumor suppression.

\section{In vivo Antitumor Activity in Orthotopic Glioma Model}

An orthotopic glioma-bearing mouse model was used in this study (Figure 5A). To investigate the ability of NPs to cross the blood-brain barrier, in vivo distribution of NPs and their accumulation in the brain were measured $24 \mathrm{~h}$ after administration (Figure 5B and C). Bare NPs could hardly be detected in the brain due to the existence of the BBTB. However, membrane wrapped NPs showed increased accumulation in glioma because PCNPs could traverse the BBTB by receptormediated transcytosis.

Kaplan-Meier plots were used for survival analysis to investigate the in vivo anti-glioma efficacy of $\beta$-PCNPs in orthotopic C6 glioma-bearing mouse model. Mice were randomly divided into six groups and treated with PBS, free $\beta$-mangostin, $\beta$-NPs, $\beta$-PNPs, $\beta$-CNPs, and $\beta$-PCNPs at a single dose of $5 \mathrm{mg} / \mathrm{kg} \beta$-mangostin, which was administered 10 days after implantation of the $\mathrm{C} 6$ cell suspension. At this stage, the BBTB is considered as the main obstacle for nanocarriers. As depicted in Figure 5D, free $\beta$-mangostin exhibited only a mild therapeutic effect. Similarly, because of the short half-life and poor specific targeting ability, a limited improvement in efficacy was observed in $\beta$-NP, $\beta$ PNP, and $\beta$-CNP groups. Notably, compared to the 26-day median survival time of the untreated group, $\beta$-PCNPs significantly prolonged median survival time to 33 days ( $\beta$ PCNPs vs all other groups, $\mathrm{p}<0.05)$. Brain glioma sections from each group were stained with hematoxylin and eosin (H\&E) to observe the tumor growth (Figure 5E). Furthermore, to evaluate the in vivo biocompatibility and 
A

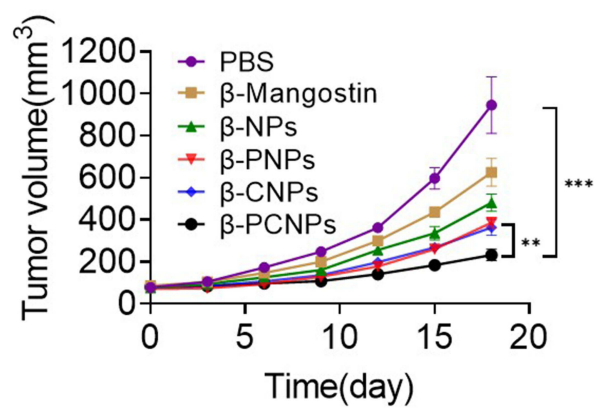

C

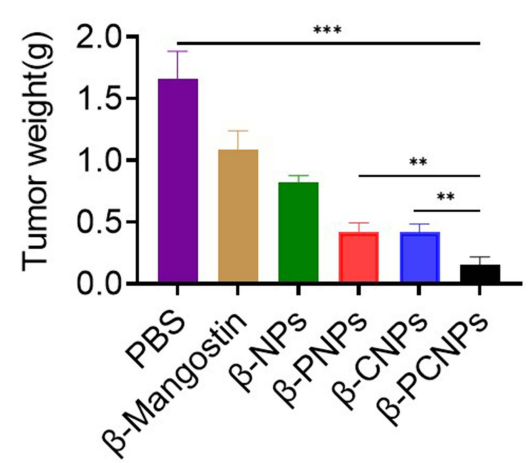

E

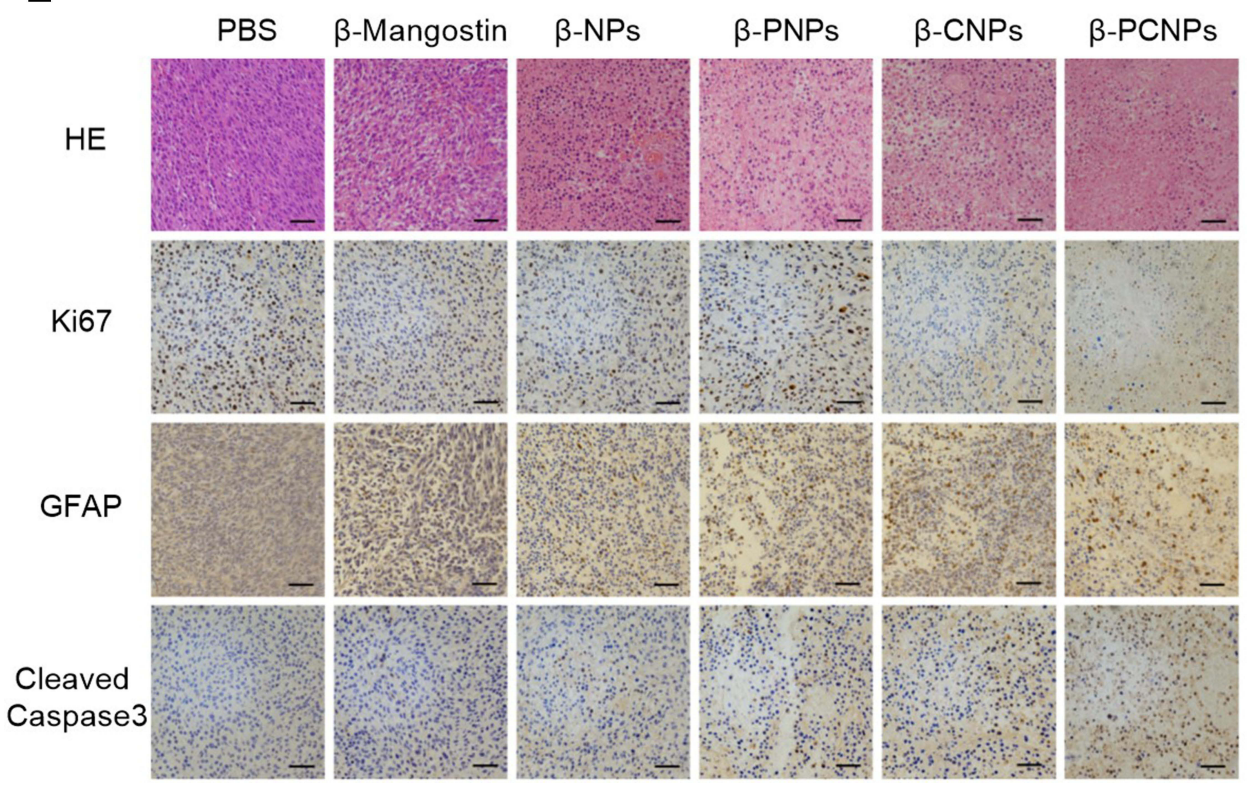

B

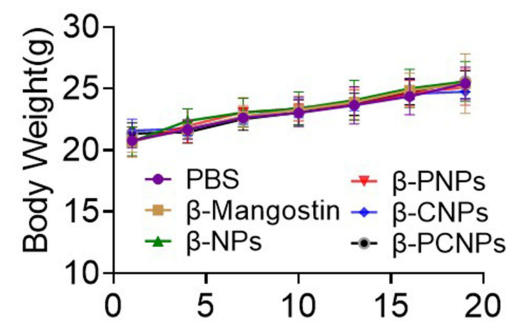

D

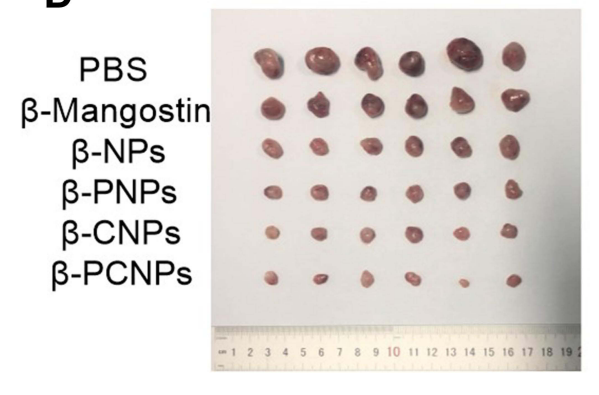

Mangostin

$\beta$-NPs

$\beta$-PNPs

$\beta$-CNPs

-PCNPs

. 
A

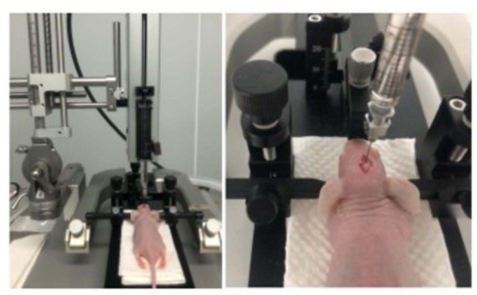

C

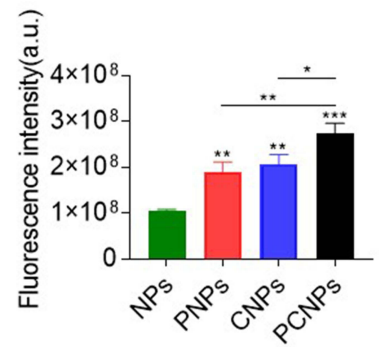

E

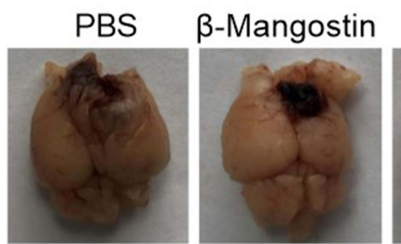

B
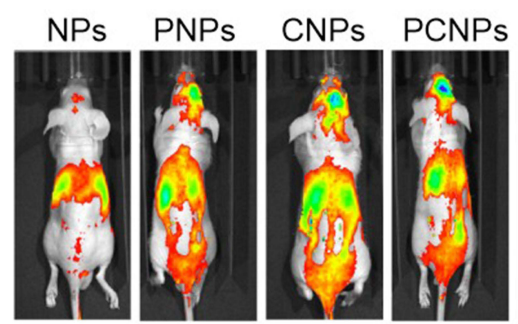

D

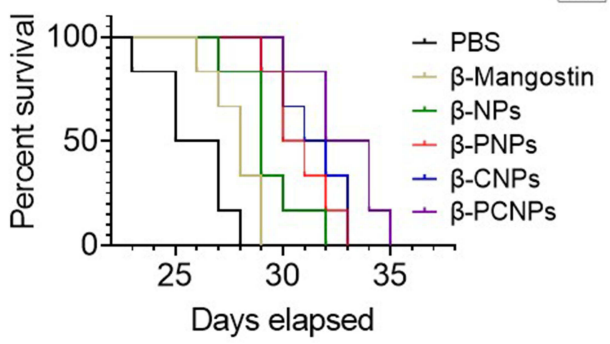

$\beta$-PNPs

$\beta$-PCNPs

$\beta$-CNPs
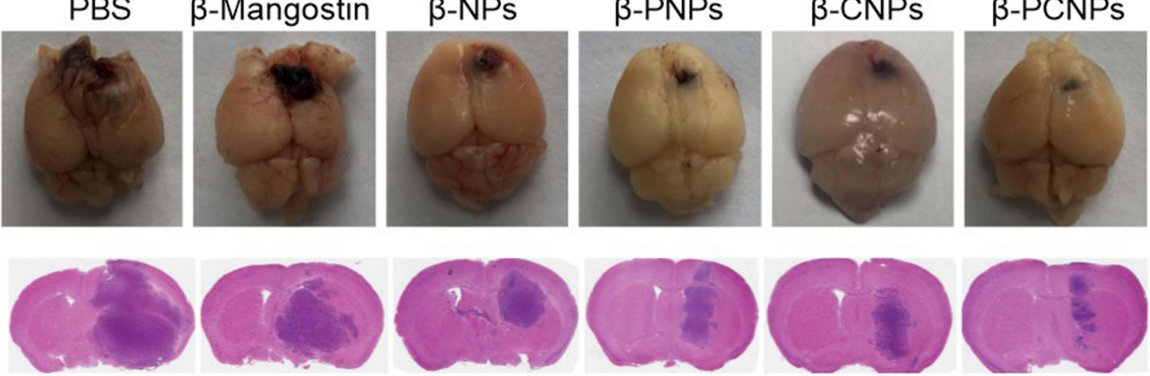

is
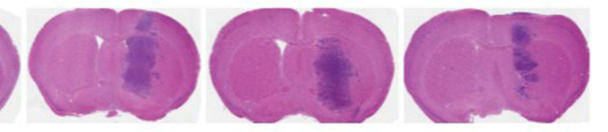

Figure $5 \beta$-Mangostin-loaded nanoparticles inhibit the growth of glioma cells in an orthotopic glioma model. (A) Schematic diagram of glioma model. (B) Representative fluorescence images of orthotopic C6 glioma mouse models from different groups. (C) Quantitative fluorescence signal intensity in the brain. (D) Survival rate curves for each test group. (E) Images of tumors and H\&E stained brain sections from all groups on day 20. Data are presented as the mean \pm S. D. of three independent experiments; $* p<0.05, * * p<0.01$, $* * * p<0.001$.

novel and efficient drug delivery systems that can traverse the $\mathrm{BBB}$ and target the intracranial tumors are highly desired for the treatment of malignant glioma.

In recent years, a number of different strategies have been developed and tried to overcome the BBB and deliver relevant drugs to brain tumors. ${ }^{36,37} \mathrm{Lu}$ et al developed a disulfide bond-conjugated prodrug polymer (CPT-S-S-PEG-iRGD@IR780 micelles) consisting of camptothecin (CPT), polyethylene glycol (PEG), and iRGD peptide, which could effectively cross barriers to reach the glioma site; moreover, they reported that antitumor effect was significantly enhanced when tumors were irradiated by laser. ${ }^{38}$ Drug targeting to tumors is highly dependent on the density of expression of specific receptors on the surface of tumor cells. ${ }^{39}$ Keeping this in mind, we developed hybrid cell membrane-coated NPs. The core NPs were formulated using FDA-approved biodegradable polymer PLGA and were loaded with $\beta$ mangostin extracted and purified from mangosteen, which has previously shown good biocompatibility and bioactivity against glioma cells. These NPs were then coated with platelet-C6 hybrid membranes for efficient treatment of glioma.

TEM images showed that the platelet-C6 hybrid membrane-camouflaged NPs (PCNPs) prepared in this study had an average diameter of $130 \mathrm{~nm}$, with approximately a 10-nmthick outer shell indicating the presence of a hybrid membrane on NP surface. SDS-PAGE results showed that the surface proteins of cell membranes were completely retained on the nanocarriers, which agrees with the results of previous studies. ${ }^{40}$ Several studies have shown that antitumor responses are associated with the adaptive immune system, which affects the delivery of drugs by immunocytes. ${ }^{41,42}$ Flow cytometry and confocal microscopy were used to evaluate the endocytosis of NPs, which plays a significant role in the immune escape property. We found that PCNPs were taken up by THP-1 cells to a much lesser extent than NPs, PNPs, and CNPs; however, PCNPs were easily taken up by C6 cells. Moreover, PCNPs had prolonged blood circulation time and showed enhanced tumor targeting (Figure S6). Fluorescence imaging showed 
that accumulation of nanocarriers in the brain glioma at 24 $\mathrm{h}$ after tail vein injection of PCNPs was 2.6-fold higher than that in cells treated with NPs. This higher accumulation was similar to that reported recently for camouflaged nanocarriers. ${ }^{43,44}$

Apoptosis is programmed cell death, which plays a critical role in maintaining normal development and cell homeostasis. ${ }^{45}$ The induction of apoptosis in tumor cells is a promising approach for tumor therapy. ${ }^{46}$ Our previous studies have shown that the apoptosis of glioma cells by $\beta$ mangostin treatment is accompanied by BAX mitochondrial distribution, oligomerization, and caspase 3 activation. ${ }^{31}$ Physical and chemical properties of $\beta$-mangostin can be effectively improved by encapsulation into NPs. CCK8 assay showed that $\beta$-PCNPs significantly inhibited the proliferation of C6 glioma cells as compared with that by both bare core NPs and single cell membrane-coated NPs. $\beta$-PCNPs induced the highest level of apoptosis in C6 cells, indicating that the delivery of $\beta$-mangostin, mediated by hybrid membranecoated NPs, increased its efficacy of inducing cell apoptosis. This was also consistent with the results of the TUNEL assay.

In $\mathrm{C} 6$ subcutaneous tumor mouse model, the average tumor volume of $\beta$-PCNP group $\left(232.3 \pm 49.7 \mathrm{~mm}^{3}\right)$ on the 18th day of dosing was significantly smaller than that of the untreated group $\left(945.3 \pm 199.0 \mathrm{~mm}^{3}\right)$. To further evaluate the antitumor effect of $\beta$-PCNPs in a clinically relevant model, we transplanted $\mathrm{C} 6$ cells into the right striatum to establish an orthotopic glioma mouse model. The untreated mice had a median survival of 26 days, which was in agreement with a previous study by Zing et al. ${ }^{47}$ Zing found that the median survival was 27 days in the anti-PD-1 antibody arm and 28 days in the radiation arm; however, treatment with $\beta$-PCNPs prolonged the survival to 33 days in our study. Thus, we have successfully developed hybrid biomimetic camouflaged NPs with multiple targeting capabilities and efficient delivery of $\beta$-mangostin to the tumor site. The developed NPs potently inhibited tumor growth without causing systemic adverse effects.

\section{Conclusion}

We generated platelet-cancer cell hybrid membranecoated hollow PLGA NPs loaded with $\beta$-mangostin. These $\beta$-PCNPs showed enhanced anticancer efficacy against glioma cells through homotypic cell targeting and immune escape. Long-term inhibition of tumor growth and metastasis was achieved owing to the characteristics of the hybrid membrane, and sustained clearance of the tumor cells by $\beta$-mangostin was observed. The high biocompatibility and excellent efficacy of $\beta$-PCNPs make them highly promising candidates for glioma treatment.

\section{Funding}

This work was supported by grants from the National Natural Science Foundation of China (81772664) Zhejiang Medical and Health Science and Technology Project (2018KY868, 2019KY017). Key projects jointly constructed by the Ministry and the province of Zhejiang Medical and Health Science and Technology Project (WKJ-ZJ-2019). Key and Major Projects of Traditional Chinese Medicine Scientific Research Foundation of Zhejiang Province (2019ZZ001, 2018ZY001). Key projects jointly constructed by the Medicine and Health Research Foundation of Zhejiang Province (WKJ-ZJ-2101).

\section{Disclosure}

The authors report no potential conflicts of interest in this work.

\section{References}

1. Wirsching HG, Galanis E, Weller M. Glioblastoma. Handb Clin Neurol. 2016;134:381-397.

2. Ellison DW. Multiple molecular data sets and the classification of adult diffuse gliomas. $N$ Engl $J$ Med. 2015;372(26):2555-2557. doi:10.1056/NEJMe1506813

3. Afshari A, Mollazadeh H, Henney N, Jamialahmad T, Sahebkar A. Effects of statins on brain tumors: a review. Semin Cancer Biol. 2020;73:116-133. doi:10.1016/j.semcancer.2020.08.002

4. Fu S, Liang M, Wang Y, et al. Dual-modified novel biomimetic nanocarriers improve targeting and therapeutic efficacy in glioma. ACS Appl Mater Interfaces. 2019;11(2):1841-1854. doi:10.1021/ acsami.8b18664

5. Yang M, Li J, Gu P, Fan X. The application of nanoparticles in cancer immunotherapy: targeting tumor microenvironment. Bioact Mater. 2021;6(7):1973-1987. doi:10.1016/j.bioactmat.2020.12.010

6. Shaw T, Mandal D, Dey G, et al. Successful delivery of docetaxel to rat brain using experimentally developed nanoliposome: a treatment strategy for brain tumor. Drug Deliv. 2017;24(1):346-357. doi:10.1080/10717544.2016.1253798

7. Huo T, Yang Y, Qian M, et al. Versatile hollow COF nanospheres via manipulating transferrin Corona for precise glioma-targeted drug delivery. Biomaterials. 2020;260:120305. doi:10.1016/j.biomaterials.2020.120305

8. Gangapurwala G, Vollrath A, De San Luis A, Schubert UJP. PLA/ PLGA-based drug delivery systems produced with supercritical CO-A green future for particle formulation? Pharmaceutics. 2020;12(11):1118. doi:10.3390/pharmaceutics12111118

9. Kang Y, Holley C, Abidian M, Madhankumar AB, Connor J, Majd S. Tumor targeted delivery of an anti-cancer therapeutic: an in vitro and in vivo evaluation. Adv Healthc Mater. 2021;10(2):e2001261. doi:10.1002/adhm.202001261

10. Cano A, Ettcheto M, Chang J, et al. Dual-drug loaded nanoparticles of Epigallocatechin-3-gallate (EGCG)/Ascorbic acid enhance therapeutic efficacy of EGCG in a APPswe/PS1dE9 Alzheimer's disease mice model. J Control Release. 2019;301:62-75. doi:10.1016/j. jconrel.2019.03.010

11. Luk BT, Zhang L. Cell membrane-camouflaged nanoparticles for drug delivery. $J$ Control Release. 2015;220(Pt B):600-607. doi:10.1016/j.jconrel.2015.07.019 
12. Bu Y, Zhang X, Zhu A, Li L, Xie X, Wang S. Inside-out-oriented cell membrane biomimetic magnetic nanoparticles for high-performance drug lead discovery. Anal Chem. 2021;93(22):7898-7907. doi:10.1021/acs.analchem.1c00567

13. Xia Q, Zhang Y, Li Z, Hou X, Feng N. Red blood cell membrane-camouflaged nanoparticles: a novel drug delivery system for antitumor application. Acta Pharm Sin B. 2019;9(4):675-689. doi:10.1016/j.apsb.2019.01.011

14. Kang T, Zhu Q, Wei D, et al. Nanoparticles coated with neutrophil membranes can effectively treat cancer metastasis. ACS Nano. 2017;11(2):1397-1411. doi:10.1021/acsnano.6b06477

15. Li M, Li J, Chen J, et al. In situ platelet membrane biomimetic magnetic nanocarriers for targeted delivery and generation of nitric oxide in early ischemic stroke. ACS Nano. 2020;14(2):2024-2035. doi:10.1021/acsnano.9b08587

16. Oroojalian F, Beygi M, Baradaran B, Mokhtarzadeh A, Shahbazi MJS Immune cell membrane-coated biomimetic nanoparticles for targeted cancer therapy. Small. 2021;17:e2006484. doi:10.1002/smll.202006484

17. Yang R, Xu J, Xu L, et al. Cancer cell membrane-coated adjuvant nanoparticles with mannose modification for effective anticancer vaccination. ACS Nano. 2018;12(6):5121-5129. doi:10.1021/acsnano.7b09041

18. Wu M, Le W, Mei T, et al. Cell membrane camouflaged nanoparticles: a new biomimetic platform for cancer photothermal therapy. Int J Nanomedicine. 2019;14:4431-4448. doi:10.2147/IJN.S200284

19. Hu Q, Zhang X, Jia L, et al. Engineering biomimetic graphene nanodecoys camouflaged with the EGFR/HEK293 cell membrane for targeted capture of drug leads. Biomaterials Science. 2020;8 (20):5690-5697. doi:10.1039/D0BM00841A

20. Bu Y, Hu Q, Zhang X, Li T, Xie X, Wang S. A novel cell membrane-cloaked magnetic nanogripper with enhanced stability for drug discovery. Biomaterials Science. 2020;8(2):673-681. doi:10.1039/C9BM01411J

21. Wang Y, Luan Z, Zhao C, Bai C, Yang K. Target delivery selective CSF-1R inhibitor to tumor-associated macrophages via erythrocyte-cancer cell hybrid membrane camouflaged $\mathrm{pH}$-responsive copolymer micelle for cancer immunotherapy. Eur J Pharm Sci. 2020;142:105136. doi:10.1016/j.ejps.2019.105136

22. Dehaini D, Wei X, Fang R, et al. Erythrocyte-platelet hybrid membrane coating for enhanced nanoparticle functionalization. $A d v$ Materials. 2017;29:16.

23. Ji B, Cai H, Yang Y, et al. Hybrid membrane camouflaged copper sulfide nanoparticles for photothermal-chemotherapy of hepatocellular carcinoma. Acta Biomater. 2020;111:363-372. doi:10.1016/j. actbio.2020.04.046

24. Cai C, Wu Q, Hong $\mathrm{H}$, et al. In silico identification of natural products from Traditional Chinese Medicine for cancer immunotherapy. Sci Rep. 2021;11(1):3332. doi:10.1038/s41598-021-82857-2

25. Xiong Y, Gao M, van Duijn B, Choi H, van Horssen F, Wang M. International policies and challenges on the legalization of traditiona medicine/herbal medicines in the fight against COVID-19. Pharmacol Res. 2021;166:105472. doi:10.1016/j.phrs.2021.105472

26. Liao X, Gao Y, Zhao H, et al. Cordycepin Reverses Cisplatin Resistance in Non-small Cell Lung Cancer by Activating AMPK and Inhibiting AKT Signaling Pathway. Front Cell Dev Biol. 2020;8:609285. doi:10.3389/fcell.2020.609285

27. Aizat WM, Ahmad-Hashim FH, Syed Jaafar SN. Valorization of mangosteen, "The Queen of Fruits," and new advances in postharvest and in food and engineering applications: a review. J Adv Res. 2019;20:61-70. doi:10.1016/j.jare.2019.05.005

28. Huang CF, Teng YH, Lu FJ, et al. $\beta$-mangostin suppresses human hepatocellular carcinoma cell invasion through inhibition of MMP-2 and MMP-9 expression and activating the ERK and JNK pathways. Environ Toxicol. 2017;32(11):2360-2370. doi:10.1002/tox.22449

29. Lee K, Ryu H, Oh S, et al. Depigmentation of $\alpha$-melanocyte-stimulating hormone-treated melanoma cells by $\beta$-mangostin is mediated by selective autophagy. Exp Dermatol. 2017;26(7):585-591. doi:10.1111/exd.13233
30. Cs L, Cl L, Th Y, et al. $\beta$-Mangostin inhibits the metastatic power of cervical cancer cells attributing to suppression of JNK2/AP-1/Snail cascade. J Cell Physiol. 2020;1:5548.

31. Li K, Wu L, Chen Y, et al. Cytotoxic and Antiproliferative Effects of $\beta$-Mangostin on Rat C6 Glioma Cells Depend on Oxidative Stress Induction via PI3K/AKT/mTOR Pathway Inhibition. Drug Des Devel Ther. 2020;14:5315-5324. doi:10.2147/DDDT.S278414

32. Zhou H, Fan Z, Lemons P, Cheng HJT, Facile A. Approach to Functionalize Cell Membrane-Coated Nanoparticles. Theranostics. 2016;6(7):1012-1022. doi:10.7150/thno.15095

33. Li J, Liu X, Qiao Y, et al. Association Between Genetic Variant in the Promoter of Pri-miR-34b/c and Risk of Glioma. Front Oncol. 2018;8:413. doi:10.3389/fonc.2018.00413

34. Jiao X, Yu Y, Meng J, et al. Dual-targeting and microenvironment-responsive micelles as a gene delivery system to improve the sensitivity of glioma to radiotherapy. Acta Pharm Sin B. 2019;9(2):381-396. doi:10.1016/j.apsb.2018.12.001

35. Zeiadeh I, Najjar A, Karaman R. Strategies for Enhancing the Permeation of CNS-Active Drugs through the Blood-Brain Barrier: a Review. Molecules. 2018;23:6. doi:10.3390/molecules23061289

36. Zhou X, Smith Q, Liu X. Nanobiotechnology. Brain penetrating peptides and peptide-drug conjugates to overcome the blood-brain barrier and target CNS diseases. Wiley Interdiscip Rev Nanomed Nanobiotechnol. 2021;13:e1695. doi:10.1002/wnan.1695

37. Su Z, Xing L, Chen Y, et al. Lactoferrin-modified poly(ethylene glycol)-grafted BSA nanoparticles as a dual-targeting carrier for treating brain gliomas. Mol Pharm. 2014;11(6):1823-1834. doi: $10.1021 / \mathrm{mp} 500238 \mathrm{~m}$

38. Lu L, Zhao X, Fu T, et al. An iRGD-conjugated prodrug micelle with blood-brain-barrier penetrability for anti-glioma therapy. Biomaterials. 2020;230:119666. doi:10.1016/j.biomaterials.2019.119666

39. Ferraris C, Cavalli R, Panciani P, Battaglia L. Overcoming the blood-brain barrier: successes and challenges in developing nanoparticle-mediated drug delivery systems for the treatment of brain tumours. Int J Nanomedicine. 2020;15:2999-3022. doi:10.2147/IJN.S231479

40. He H, Guo C, Wang J, et al. Leutusome: a biomimetic nanoplatform integrating plasma membrane components of leukocytes and tumor cells for remarkably enhanced solid tumor homing. Nano Lett. 2018;18(10):6164-6174. doi:10.1021/acs.nanolett.8b01892

41. Jia Y, Wang X, Hu D, et al. Phototheranostics: active targeting of orthotopic glioma using biomimetic proteolipid nanoparticles. ACS Nano. 2019;13(1):386-398. doi:10.1021/acsnano.8b06556

42. Chen Z, Zhao P, Luo Z, et al. Cancer cell membrane-biomimetic nanoparticles for homologous-targeting dual-modal imaging and photothermal therapy. ACS Nano. 2016;10(11):10049-10057. doi:10.1021/acsnano.6b04695

43. Han L, Xu Y, Guo X, Yuan C, Mu D, Xiao Y. Cancer cell membrane-coated biomimetic platform for targeted therapy of breast cancer in an orthotopic mouse model. J Biomater Sci Polym Ed. 2020;31(12):1538-1551. doi:10.1080/09205063.2020.1764163

44. Wang H, Wu J, Williams GR, et al. Platelet-membrane-biomimetic nanoparticles for targeted antitumor drug delivery. J Nanobiotechnology. 2019;17(1):60. doi:10.1186/s12951-019-0494-y

45. Xu X, Lai Y, Hua ZC. Apoptosis and apoptotic body: disease message and therapeutic target potentials. Biosci Rep. 2019;39(1). doi:10.1042/BSR20180992

46. Lu W, Sun Q, Chen B, Li Y, Xu Y, Wang S. Novel agent \#2714 potently inhibits lung cancer growth by suppressing cell proliferation and by inducing apoptosis in vitro and in vivo. Mol Med Rep. 2019;19(6):4788-4796. doi:10.3892/mmr.2019.10114

47. Zeng J, See AP, Phallen J, et al. Anti-PD-1 blockade and stereotactic radiation produce long-term survival in mice with intracranial gliomas. Int $J$ Radiat Oncol Biol Phys. 2013;86(2):343-349. doi:10.1016/j.ijrobp.2012.12.025 


\section{Publish your work in this journal}

The International Journal of Nanomedicine is an international, peerreviewed journal focusing on the application of nanotechnology in diagnostics, therapeutics, and drug delivery systems throughout the biomedical field. This journal is indexed on PubMed Central, MedLine, CAS, SciSearch ${ }^{\mathbb{R}}$, Current Contents ${ }^{\mathbb{B}} /$ Clinical Medicine,
Journal Citation Reports/Science Edition, EMBase, Scopus and the Elsevier Bibliographic databases. The manuscript management system is completely online and includes a very quick and fair peer-review system, which is all easy to use. Visit http://www.dovepress.com/ testimonials.php to read real quotes from published authors. 